KOVALENi:

\title{
PEMBUATAN Carboxymethyl cellulose (CMC) DARI PELEPAH NANAS (Ananas cosmosus Merr.)
}

\section{PRODUCTION OF Carboxy methyl cellulose (CMC) FROM PINEAPPLE MIDRIB (Ananas cosmosus Merr.)}

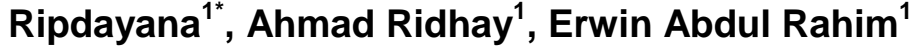 \\ 1) Jurusan Kimia, Fakultas MIPA, Universitas Tadulako, Palu \\ J. Soekarno Hatta Km.9, Kampus Bumi Tadulako Tondo Palu, Telp. 0451- 422611 \\ *)Coresponding author: ripdayana59@gmail.com (082280555077)
}

Diterima 27 Desember 2018, Disetujui 13 Juni 2019

\begin{abstract}
A research about production of Carboxymethyl cellulose (CMC) from pineapple midrib (Ananas cosmosus Merr.) has been conducted. This research aims to determine the best cellulose ratio with sodium monochloro acetate and the best reaction time to the substitution degree of carboxymethyl cellulose from pineapple midrib fibers. This study used a Completely Randomized Design method with two independent variables, i.e. variations in the weight of sodium monochloroacetate $(2.5 \mathrm{grams}$, 3 grams, 3.5 grams, 4 grams, and 4.5 grams) and variations in reaction time ( 1 hour, 2 hours, 3 hours, 4 hours, and 5 hours), each treatment was done duplo using 20 treatment units. The result of the study showed that the best ratio of sodium monochloroacetate to cellulose which produced carboxymethyl cellulose from pineapple midribs was 2.5: 2.5 with substitution degree value of 1.93 and optimum reaction time which produced carboxymethyl cellulose from pineapple midribs was 1 hour with substitution degree of 2.38 .
\end{abstract}

Keywords : Carboxymethyl cellulose, Pineapple midrib

\begin{abstract}
ABSTRAK
Telah dilakukan penelitian tentang pembuatan Carboxy methyl cellulose (CMC) Dari Pelepah nanas (Ananas cosmosus Merr.) Penelitian ini bertujuan untuk menentukan rasio selulosa dengan natrium monokloroasetat dan waktu reaksi terbaik terhadap derajat substitusi karboksilmetil selulosa dari serat pelepah nanas. Penelitian ini menggunakan Rancangan Acak Lengkap dengan dua variabel bebas yaitu variasi bobot natrium monokloroasetat ( $2.5 \mathrm{gram}, 3 \mathrm{gram}, 3.5 \mathrm{gram}, 4 \mathrm{gram}$, dan 4.5 gram ) dan variasi waktu reaksi ( 1 jam, 2 jam, 3 jam, 4 jam, dan 5 jam), setiap perlakuan dilakukan secara duplo sehingga 20 unit perlakuan. Hasil penelitian pada rasio terbaik natrium monokloroasetat terhadap selulosa yang menghasilkan karboksimetil selulosa dari pelepah nanas yaitu $2.5: 2.5$ dengan nilai derajat substitusi sebesar 1.93 dan waktu reaksi optimum yang menghasilkan karboksimetil selulosa dari pelepah nanas yaitu 1 jam dengan nilai derajat substitusi sebesar 2.38.
\end{abstract}

Kata Kunci : Karboksimetil selulosa, pelepah nanas. 


\section{LATAR BELAKANG}

Tanaman Nanas termasuk famili Bromeliaceae merupakan tumbuhan tropis dan subtropis yang banyak terdapat di Filipina, Brasil, Hawai, India dan Indonesia. Menurut data FAO (2003), Indonesia merupakan salah satu negara penghasil nanas selain beberapa negara lainnya dengan produksi sebesar 467.395 ton. Di Indonesia, salah satu provinsi yang dikenal sebagai penghasil nanas adalah Provinsi Kalimantan Barat, yang pada tahun 2000, dengan luas lahan $1500 \mathrm{Ha}$ dapat dihasilkan sekitar 30.000 Ton nanas (Van, 2006).

Nanas didaerah Sulawesi tengah banyak tubuh di Morowali, Parigi dan Desa Lero, Kecamatan sindue. Tanaman ini tumbuh di daerah dataran rendah dan belum dimanfaatkan oleh masyarakat sekitar. Nanas banyak tumbuh di dataran rendah sampai $1000 \mathrm{~m}$ di permukaan laut, dengan suhu antara $25-35{ }^{\circ} \mathrm{C}$, sedangkan curah hujannya antara 300-500 mm perbulan selama periode pertumbuhan (Muljohardjo, 2006).

Pelepah nanas merupakan salah satu bagian tanaman yang memiliki kandungan serat yang tinggi. Wijayani et al. (2005) melaporkan bahwa terdapat $69,5-71,5 \%$ selulosa yang terkandung dalam serat pelepah nanas. Adanya kandungan selulosa dalam serat pelepah nanas yang tinggi ini diharapkan dapat dijadikan sumber selulosa sebagai carboxy methyl cellulose (CMC).
Faktor-faktor yang mempengaruhi proses pembuatan $\mathrm{CMC}$ adalah alkalisasi dan karboksimetilasi. Alkalisasi merupakan langkah untuk mengaktifkan gugus-gugus $\mathrm{OH}$ pada molekul selulosa, dengan adanya proses alkalisasi ini maka struktur selulosa akan mengembang dan akan memudahkan reagen karboksimetilasi berdifusi didalamnya. Setelah itu dilanjutkan dengan proses karboksimetilasi merupakan langkah untuk melihat jumlah asam monokloroasetat ataupun natrium monokloroasetat akan berpengaruh terhadap substitusi unit anhidroglukosa pada selulosa.

Dilihat dari fungsi Natrium Hidroksida dan Natrium Monokloroasetat maka komposisi kedua reagen baik reagen alkalisasi maupun karboksimetlilasi dalam proses ini sangat menentukan kualitas CMC yang akan dihasilkan. Berdasarkan hasil penelitian Bidin (2010), pembuatan CMC dari jerami padi dengan nilai derajat subsitusi terbaik diperoleh pada rasio natrium monokloroasetat/selulosa 6:5 dengan 4 jam waktu reaksi dengan derajat subsitusi karbosimetil selulosa sebesar 1,477. Hasil tersebut lebih baik bila dibandikan dengan penelitian sebelumnya yang dilakukan oleh Wijayani et al. (2005), yang mendapatkan nilai derajat subsitusi sebesar 0,85 yang mengunakan enceng gondok sebesar bahan dasar pembuatan karboksimetil selulosa. 


\section{METODE PENELITIAN}

\section{Bahan dan Peralatan}

Bahan dasar yang digunakan dalam penelitian ini adalah pelepah nanas yang diporoleh dari desa Lero. Bahan lainnya adalah natrium monokhloroasetat, natrium hidroksida, hidrogen peroksida, asam asetat glasial, asam nitrat, asam klorida, etanol, metanol, indikator PP dan akuades

Peralatan yang digunakan berupa Seperangkat alat Spektrofotometer Fourier Transform Infra red (FTIR) Prestige 21 Shimadzu, sendok, batang pengaduk, sendok zat, toples, baskom plastik, neraca digital Kern 440-43N, desikator, oven analitik Memmert, penangas air, hot plate Cimarec, Sieve shaker AG-515, ayakan 60 mesh, kain saring, kertas saring, kertas $\mathrm{pH}$, gunting, blender.

\section{Prosedur Penelitian}

\section{Persiapan Sampel Pelepah Nanas}

Pelepa nanas dipisahkan dari buahnya, Kemudian pelepah nanas dicuci dengan air mengalir hingga bersih. Sampel pelepah nanas terlebih dahulu dipotong-potong kemudian dijemur dibawah sinar matahari hingga kering. Sampel pelepah nanas yang telah kering ini kemudian digiling dan diayak dengan ayakan berukuran 60 mesh. Tepung pelepah nanas dikeringkan kembali dengan menggunakan oven selama 1 jam pada suhu $60^{\circ} \mathrm{C}$.
Pengukuran Kadar Air (Wijayani et al., 2005)

Sebanyak 10 gram sampel dimasukkan ke dalam cawan petri yang telah dibersihkan dan kering, selanjutnya dimasukkan ke dalam oven selama 3 jam pada suhu $105^{\circ} \mathrm{C}$, setelah itu didinginkan di dalam desikator selama 30 menit kemudian ditimbang. Cawan beserta sampel dipanaskan kembali selama 1 jam hingga diperoleh berat konstan.

Delignifikasi Selulosa (Nur'ain et al., 2016)

Serbuk pelepah nanas direndam dengan menggunakan larutan natrium hidroksida $10 \%$ dengan perbandingan pelarut $1: 10(\mathrm{~b} / \mathrm{v})$, kemudian diaduk dengan rata sampai seluruh serbuk pelepah nanas terendam sempurna. Perendaman dilakukan selama 24 jam. Setelah itu disaring dengan menggunakan kain saring. Residu yang diperoleh kemudian direndam kembali dengan menggunakan larutan hidrogen peroksida $10 \%$ perendaman ini dilakukan selama 24 jam. Kemudian campuran tersebut disaring dan residu yang dihasilkan dicuci dengan aquadest yang telah dididihkan hingga bau hidrogen peroksida hilang. Residu kemudian dimasukkan ke dalam cawan petri, lalu dikeringkan di dalam oven dengan suhu $60^{\circ} \mathrm{C}$ hingga berat konstan.

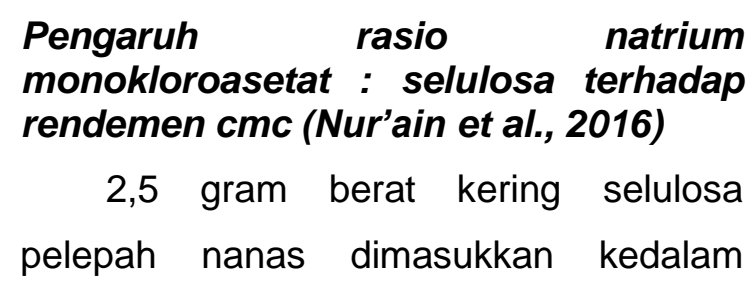


erlenmeyer $250 \mathrm{ml}$ ditambahkan $50 \mathrm{~mL}$ aquadest. Selanjutnya ditambahkan $5 \mathrm{ml}$ larutan $\mathrm{NaOH} 30 \%$ tetes demi tetes selama 1 jam. Setelah selesai dilanjutkan proses karboksimetilasi dengan menambahkan $\mathrm{ClCH}_{2} \mathrm{COONa}$ sebanyak (2,5 g). Campuran kemudian dipanaskan dengan suhu $60^{\circ} \mathrm{C}$ selama 3 jam. Setelah itu campuran disaring dan residunya direndam menggunakan $100 \mathrm{ml}$ metanol selama 24 jam. Kemudian campuran dinetralkan menggunakan larutan asam asetat glasial. Campuran kemudian disaring kembali dan residunya dikeringkan di dalam oven dengan suhu $60^{\circ} \mathrm{C}$ hingga beratnya konstan. Karboksimetil selulosa yang dihasilkan ditentukan, rendemen dan derajat subtitusinya. Perlakuan yang sama dilakukan pada rasio $\mathrm{ClCH}_{2} \mathrm{COONa}$ terhadap selulosa 2,5:3; 2,5:3,5; 2,5:4; dan 2,5:4,5 (w/w) .

\section{Pengaruh waktu reaksi terhadap rendemen CMC (Nur'ain et al., 2016)}

2,5 gram berat kering selulosa pelepah nanas dimasukkan kedalam erlenmeyer $250 \mathrm{ml}$ ditambahkan $50 \mathrm{~mL}$ aquadest. Selanjutnya ditambahkan $5 \mathrm{ml}$ larutan $\mathrm{NaOH} 30 \%$ tetes demi tetes selama 1 jam. Untuk mengetahui kondidsi optimum waktu reaksi sintesis karboksimetil selulosa, digunakan natrium monokloroasetat yang menghasilkan derajat subtitusi tertinggi dengan waku reaksi yaitu 1 jam, 2 jam, 3 jam, 4 jam dan 5 jam yang dipanaskan pada suhu $60^{\circ} \mathrm{C}$.
Campuran kemudian disaring dan residunya direndam menggunakan $50 \mathrm{ml}$ metanol selama 24 jam. Kemudian campuran dinetralkan menggunakan larutan asam asetat glasial. Campuran kemudian disaring kembali dan residunya dikeringkan di dalam oven dengan suhu $60^{\circ} \mathrm{C}$ hingga beratnya konstan. Setelah itu, karboksimetil selulosa yang dihasilkan ditentukan derajat substitusinya.

\section{Penentuan derajat substitusi (Nur'ain et al., 2016)}

Satu gram karboksimetil selulosa dicampurkan dengan $30 \mathrm{ml}$ larutan etanol 95\% sambil diaduk secara merata. Kemudian ke dalamnya ditambahkan $5 \mathrm{ml}$ larutan asam nitrat $2 \mathrm{M}$ dan campuran diaduk kembali selama 2 menit. Campuran dipanaskan selama 5 menit dan kembali diaduk selama 15 menit. Setelah itu, campuran disaring dan residunya dicuci menggunakan $15 \mathrm{ml}$ larutan etanol 95\% yang telah dipanaskan sampai $60^{\circ} \mathrm{C}$. Residu dicuci kembali dengan metanol dan dikeringkan di dalam oven pada suhu $105^{\circ} \mathrm{C}$ selama 3 jam. 0,5 g residu ditambahkan $100 \mathrm{ml}$ aquadest sambil di aduk, kemudian ditambahkan 25 $\mathrm{ml}$ larutan natrium hidroksida $0,5 \mathrm{~N}$ dan dipanaskan selama 15 menit. Dalam keadaan panas, campuran dititrasi dengan $\mathrm{HCl} 0,3 \mathrm{~N}$.

\section{Pengukuran Berat molekul (Habibah, 2013)}

Ditimbang 0,025 gram karboksimetil selulosa. Dimasukkan ke dalam labu ukur 
$25 \mathrm{~mL}$ dan dilarutkan sedikit demi sedikit dengan aquadest hingga garis batas labu takar. Setelah larut dihomogenkan campuran. Dimasukkan larutan ke dalam viskometer Ostwald. Dicatat waktu alir dari campuran tersebut. Dilakukan sebanyak tiga kali. Dilakukan prosedur yang sama untuk setiap karboksimetil selulosa dengan variasi konsentrasi larutan $(0,0375 ; 0,05 ; 0,0625 ; 0,075 ; 0,0875 ;$ dan $0,1 \mathrm{~g} / 25 \mathrm{~mL})$.

\section{HASIL DAN PEMBAHASAN}

\section{Rasio Natrium Monokloasetat dan Selulosa Terbaik}

Hasil proses dari delignifikasi serbuk pelepah nanas ini diperoleh senyawa selulosa dengan rendemen sebesar 22,1 $\%$ berwarna putih. Penelitian yang dilakukan oleh Nur'ain et al. (2016) dengan bahan yang berbeda yakni batang jagung sebesar $36,127 \%$.

Rendemen tertinggi karboksimetil selulosa terhadap pada rasio natrium monokloroasetat : selulosa 2,5:4,5 (w/w) yaitu sebesar 41,14\% (Gambar 1).

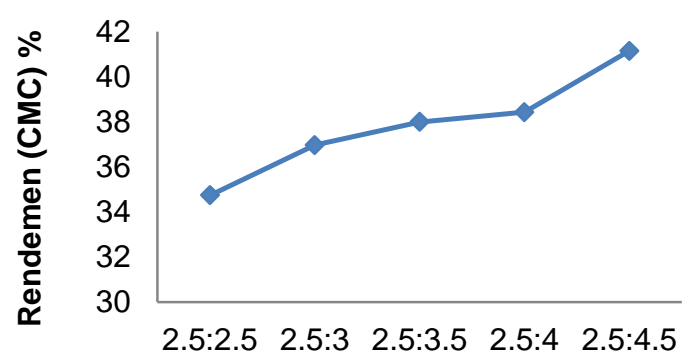

Rasio Natrium Monokloroasetat : Selulosa (b/b)

\footnotetext{
Gambar 1 Pengaruh jumlah natrium monokloroasetat terhadap rendemen $\mathrm{CMC}$ pelepah nanas.
}

Rendemen yang diperoleh pada penelitian ini lebih tinggi jika dibandingkan dengan penelitian sebelumnya yang dilakukan oleh Bidin (2010), dengan bahan pembuatan karboksimetil selulosa berasal dari selulosa jerami padi diperoleh rendemen tertinngi pada penambahan 6 gram nantrium monokloroasetat yaitu sebesar $67,52 \%$ dan penelitian dari Melisa (2014), dengan bahan pembuatan karboksimetil selulosa berasal dari tongkol jagung manisan diperoleh rendemen tertinggi pada penambahan 7 gram natrium monokloroasetat yaitu sebesar $69,73 \%$.

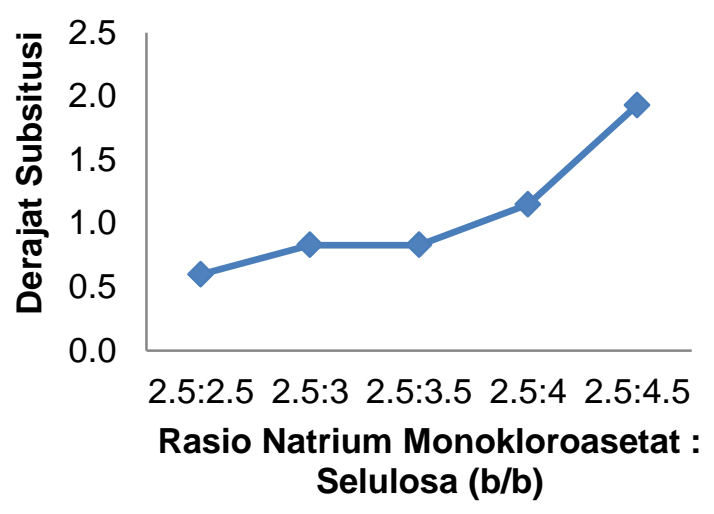

Gambar 2 Pengaruh jumlah natrium monokloroasetat terhadap derajat substitusi CMC dari pelepah nanas

Hasil terbaik pada pembuatan CMC dari pelepah nenasyaitu pada rasio natrium monokloroasetat : selulosa 2,5:4,5 gram dengan rendemen yang didapatkan sebesar 41,14 \% dengan nilai derajat substitusi sebesar 1,93 (Gambar 2). Jika dibandingkan dengan penelitian sebelumnya yang dilakukan oleh Nur'ain et al. (2016), dengan bahan pembuatan karboksimetil selulosa berasal dari selulosa tongkol jagung derajat substitusi 
tertinggi yaitu sebesar 0,839. Menurut Aambjornsson et al. (2013), nilai derajat substitusi maksimum secara teori untuk CMC adalah 3, dengan rata-rata nilai derajat substitusi 0,4-1,5. Semakin tinggi nilai derajat substitusi, maka kelarutan CMC dalam air akan meningkat. Derajat substitusi yang dihasilkan pada penelitian ini berkisar antara 0,60-1,93.

\section{Waktu Reaksi Sntensis Krboksimetil Selulosa (CMC) Optimum}

Rendemen tertinggi terdapat pada waktu reaksi selama 5 jam yaitu 45,41\% (Gambar 3). Jika dibandikan dengan penelitian sebelumnya yang dilakukan oleh Nur'ain et al. (2016), dengan bahan pembuatan karboksimetil selulosa berasal dari selulosa tongkol jagung diperoleh rendemen tertinggi pada penambahan 6 gram natrium monokloroasetat yaitu sebesar $91,95 \%$.

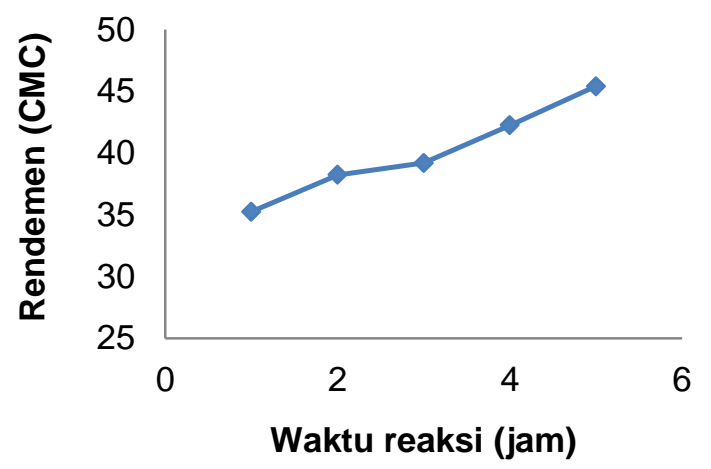

Gambar 3 Pengauh waktu reaksi terhadap rendemen CMC dari pelepah nanas

Derajat subtitusi CMC pada waktu 5 jam mampu dihasilkan pada tingkat 2,38 (Gambar 4). Tingginya nilai derajat subtitusi dari CMC pelapah nenas, sehingga diasumsikan memiliki kelarutan yang tinggi dalam air.

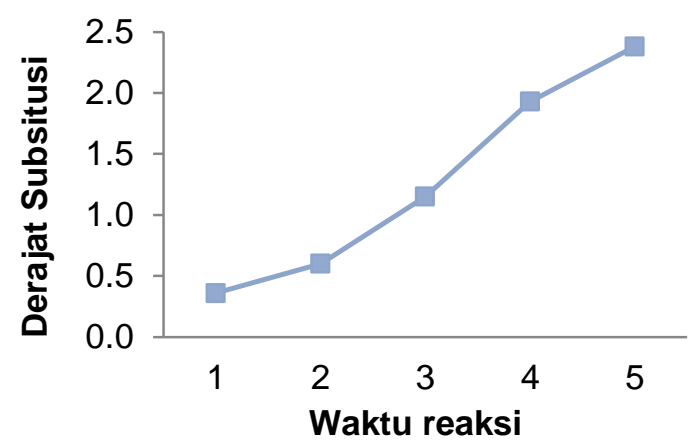

Gambar 4 Pengaruh waktu reaksi terhadap derajat substitusi CMC dari pelepah nanas

\section{Berat Melekul CMC}

Berat molekul karboksimetil selulosa (CMC) yang diperoleh pada waktu reaksi optimum adalah $6.120,962 \mathrm{~g} / \mathrm{mol}$. Nilai berat molekul yang didapatkan jauh lebih kecil dari berat molekul yang disyaratkan yaitu 90000 g/mol. USP (United States Pharmacopeia) mendeskripsikan sodium karboksimetil selulosa merupakan garam sodium yang berasal dari sebuah polikarboksimetil eter selulosa. Berat molekulnya adalah 90000-700000 g/mol. Menurut penelitian yang dilakukan oleh Awaludin et al. (2004), karboksimetil selulosa (CMC) dari selulosa bakteri memiliki berat molekul $48.885 \mathrm{~g} / \mathrm{mol}$, sedangkan karboksimetil selulosa (CMC) dari selulosa tumbuhan memiliki berat molekul $34.235 \mathrm{~g} / \mathrm{mol}$.

\section{KESIMPULAN}

Rasio terbaik antara natrium monokloroasetat terhadap selulosa yang menghasilkan karboksimetil selulosa dari pelepah nanas, yaitu 2,5: 4,5 (w/w) 
selama 5 jam dengan nilai derajat substitusi sebesar 2,38 dan rendemen $45,41 \%$ serta berat molekul $6.120,962$ $\mathrm{g} / \mathrm{mol}$.

\section{DAFTAR PUSTAKA}

Aambjornsson, H.,K. Schenzel., U. Germgard. 2013. Carboxymethyl Cellulose Produced at Different Mercerization Condition and Caracterized by NIRFT Raman Spectroscopy in Combination Multivariate Analytical Methods. Bioresources 8: 1918-1932.

Bidin, A. 2010. Optimasi Kondisi Reaksi Sintesis Karboksimetil Selulosa Dari Jerami Padi (Oryza sativa). Skripsi. Palu: Universitas Tadulako.

Habibah, Djati U. 2013. Konversi Selulosa dari Biomassa Batang Pisang Menjadi Asam Levulinat Melalui Reaksi Katalitik Dengan Katalis Kromium. Skripsi. Bandung: Universitas Pendidikan Indonesia.

Melisa, 2014, Optimasi Sintesis Karboksimetil Selulosa Dari Tongkol Jagung (Zea Mays L Saccharata), Jurnal of natural science, 3 (2): 70-78.

Muljohardjo. 2000. Potensi Investasi Subsektor Tanaman Pangan dan Hortikultur di Kalimantan Barat. Pontianak: Disperta Propinsi Kalimantan Barat.

Nur'ain., Nurhaeni., Ridhay, A. 2016. Optimasi Kondisi Reaksi Untuk Sintesis Karboksimetil Selulosa (CMC) Dari Batang Jagung (Zea mays L.). KOVALEN, 3(2): 112-121.

Van, A. T. 2006. Chemical Analysis and Pulping Study of Pineapple Crown Leaves. Industrial Crops and
Products. An International Journal. 24:66-74

Wijayani, A., Khoirul U., Siti T. 2005. Karakterisasi Karboksimetil Selulosa $\mathrm{CMC}$ ) dari Eceng Gondok (Eichornia crassipes (Mart) Solms). Indo. J. Chem., 5 (3): 228 - 231. 